\title{
Monetary evaluation methodology in the project management
}

\author{
Elena Akimova ${ }^{1, *}$ and Galina Potasheva ${ }^{1}$ \\ ${ }^{1}$ Moscow State University of Civil Engineering, Yaroslavskoeshosse, 26, Moscow, 129337, Russia
}

\begin{abstract}
This article considers the monetary evaluation methodology in the project management, which allows considering the strategic management from the viewpoint of designing, where the designing represents a specific branch of system engineering focused on the creation through the formation of requirements to technology, i.e. determination of its functions at the project "input" and allocation of the structure at the "output" as a final result of the designing in the conditions of modern urban location. The article also considers the risk analysis and monetary evaluation in the project management.
\end{abstract}

\section{Introduction}

The strategic management of complex systems, as it considers R. M. Grant, is carried out through a combination of centralized management from the top and decentralized, accidental management from the bottom, is confirmed by the complexity theory, wherein the system adaptation is achieved through random processes, where the total effectiveness of adaptation is ensured through moderate levels of the adaptive intensity and rules facilitating the coordination. The complexity theory describes the behavior of such systems and their common features:

Unpredictability - the behavior of complex systems is difficult to predict. There is no tendency toward a stable equilibrium. Changes interact with each other, lead to minor changes, but can lead to major changes too. Self-organization - features of systems is their capability to self-organization, so organizations tend to self-organization, adapt to changes and create new systems. Inertia and chaos - changes may lead: to the order, limiting changes and leading to inertia; to the disorder - to the chaos, wherein minor changes, which lead to the distribution in the power-law dependence, generate shifts and form the evolutionary adaptation. Development on the brink of chaos - systems are capable to adapt, but have the possibility to evolve to higher levels, and in the lack of correspondence transform into the chaos. Business is a complex system and is originally unpredictable; therefore, it is necessary to rely on the organization's capabilities to tend to the selforganization. The feature is that it is necessary to design such systems which will allow obtaining the maximum opportunity of enterprise activity effectiveness increase. Based on the results of Brown, Eisenhardt, McKelvey and Levinthal studies, the following

\footnotetext{
*Corresponding author: kima@mail.ru
} 
recommendations on how organizations can achieve the effectiveness on the brink of chaos can be given:

Establish simple rules, since sometimes an organization does not plan a strategy, but creates rules guiding its activities, where there are opportunities. These rules of sorting opportunities ("boundary rules") will allow definition of the general approach to how organization will use its possibilities (rules of "how to do" type), set priorities at allocation of resources ("rules of priority"), in other words, it is needed to establish conditions for consistent and drastic changes.

Speed up the development the help of a flexible organizational structure which is getting strict due to the power center formation while the interactions are getting institutional, which will eventually become more rigid as the power center forms, and interactions become institutional. So Eisenhardt and Brown use the term "put on patches" to describe the process in which new organizational units are continuously created, merged and revised, what contributes to demonstration of flexibility. Use adaptive intensity to balance on the brink of chaos, bearing in mind that the shortage of intensity creates inertia, and its excess entails chaos. Therefore, it is needed to provide such level of intensity which will allow optimizing the rate of organizational changes and innovations $[4,16]$.

\section{Methodology}

Therefore, it is needed to approach the strategic management from the project aspect, where the project is considered as a set of interrelated procedures for achievement of the set targets to the extent of limits of time, budget and expected results. The project passes its life cycle; it has its own regularities and specific management methods. The project approach assumes the system designing based on the interconnection of object and design process. The design process management structure consists of the following stages:

Target setting and formation of technical specifications;

Internal designing includes the operating principle synthesis stages (standards, laws and regulations), structures (diagrams, algorithms, sketches) and designed object parameters (numerical solution of the design task is found). Effectiveness of the designing is determined by: selected operating principle, proposed structure and correlation of parameters.

When designing, it is needed to take into account the following regularities, considered by G. S. Altshuller and A. I. Polovinkin [11]: regularity of the "energy conductivity" of the system, which states that the necessary condition of system feasibility is the pass of energy throughout all parts of the system; regularity of system perfectness increase - systems formation is carried out in the direction of the perfectness degree increase when weight, volume or sizes of the system tend to the best value, and the function is kept and executed; regularity of stage development - development of systems proceeds in a certain sequence; regularity of correspondence of function and structure - viable happen to be those systems, which have the form subjected to the internal content and meeting the specified requirements. A system approach defined the designing as a sort of system modelling, where the design business is understood as a kind of business, which is based on the use of one of the design models. The strategy development methodology based on the implementation of projects and programs must be used in the strategic designing (Figure 1) [1]. To solve the designing problem within the framework of design aspects, the methodology of balanced system of indicators (BSI) can be used, which mechanism is the following: key performance indicators are set; their target values by strategy implementation years are defined; responsible managers are appointed; procedures and projects are designed (strategic initiatives), which are to be realized in order to attain the targets; resources for the implementation of strategic initiatives are calculated (Figure 2). In 
the balanced system of indicators the strategic initiatives impart acceleration to the system, which allows overcoming the inertia and resistance to changes [1]. For effective implementation of the projects, it is needed to use the international project management methodologies. Standards in the field of project management are presented in Figure 3 [15].

Design technology is stated in the Project management body of knowledge (PMBOK, fourth edition) - a standard of project management in various areas of activity. Standard reflects the requirements to projects, programs and portfolios of projects, which allow fulfilment of strategic targets. However, this knowledge is not enough for effective project management. It is necessary to use the knowledge's and skills of more five expert areas, which allow designing the organization as a whole, creating the project business: project management body of knowledge; knowledge's and skills in the field of project management; knowledge's, standards and regulations for project management; analysis of external environment of the project; team building skills.

\section{Results}

Designing represents a specific sector of system engineering, focused on the creation by setting requirements to the technology, i.e. definition of its functions at the project "input" and allocation of the structure at the project "output" as a final result of designing. S. A. Mishin developed the business designing methodology called OOAP (object-oriented analysis and programming (OOAP)), that enables building models of business systems and developing programs for automation of work [11]. In this methodology, a business system is apportioned into components (classes) on the basis of hierarchic relations. The description of each class is made through the properties, methods and events, because objects of the same class have the same properties. Methods designate operations which are made with classes. The methods allow designing new objects, forming their properties and modifying them. The hierarchic structure of the project business algorithm is shown in Figure 4.

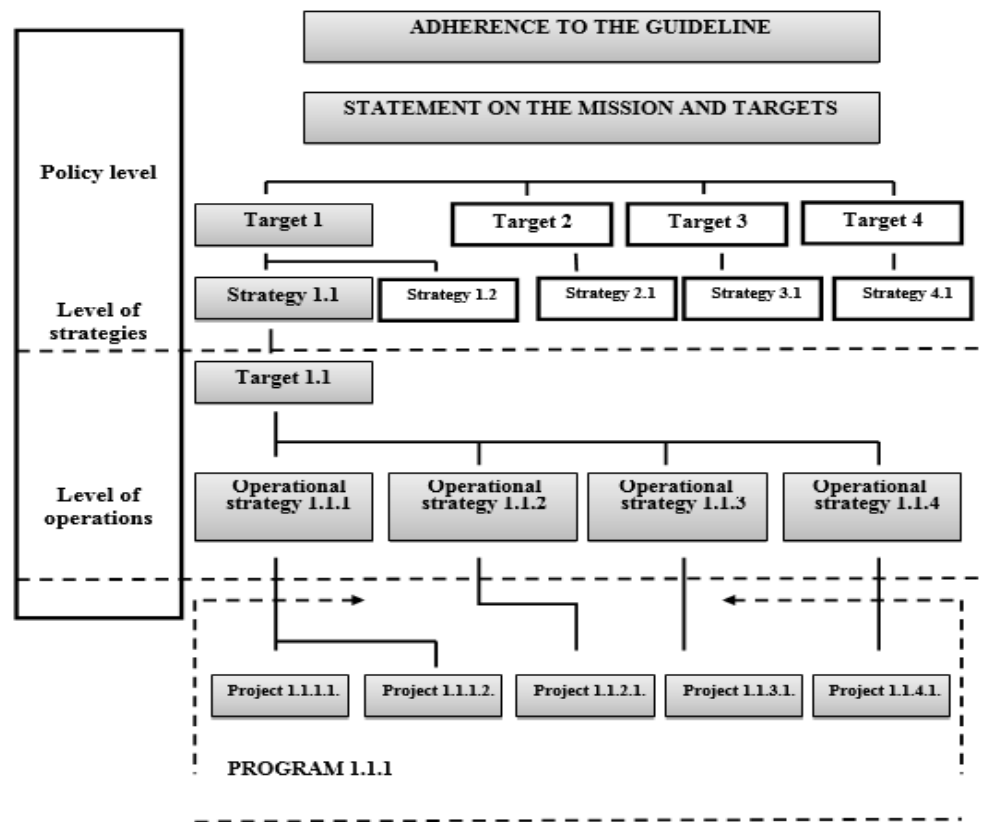

PORTFOLIO OF PROJECTS FOR TARGET 1.1

Fig.1. Transformation of targets and strategies in projects. 


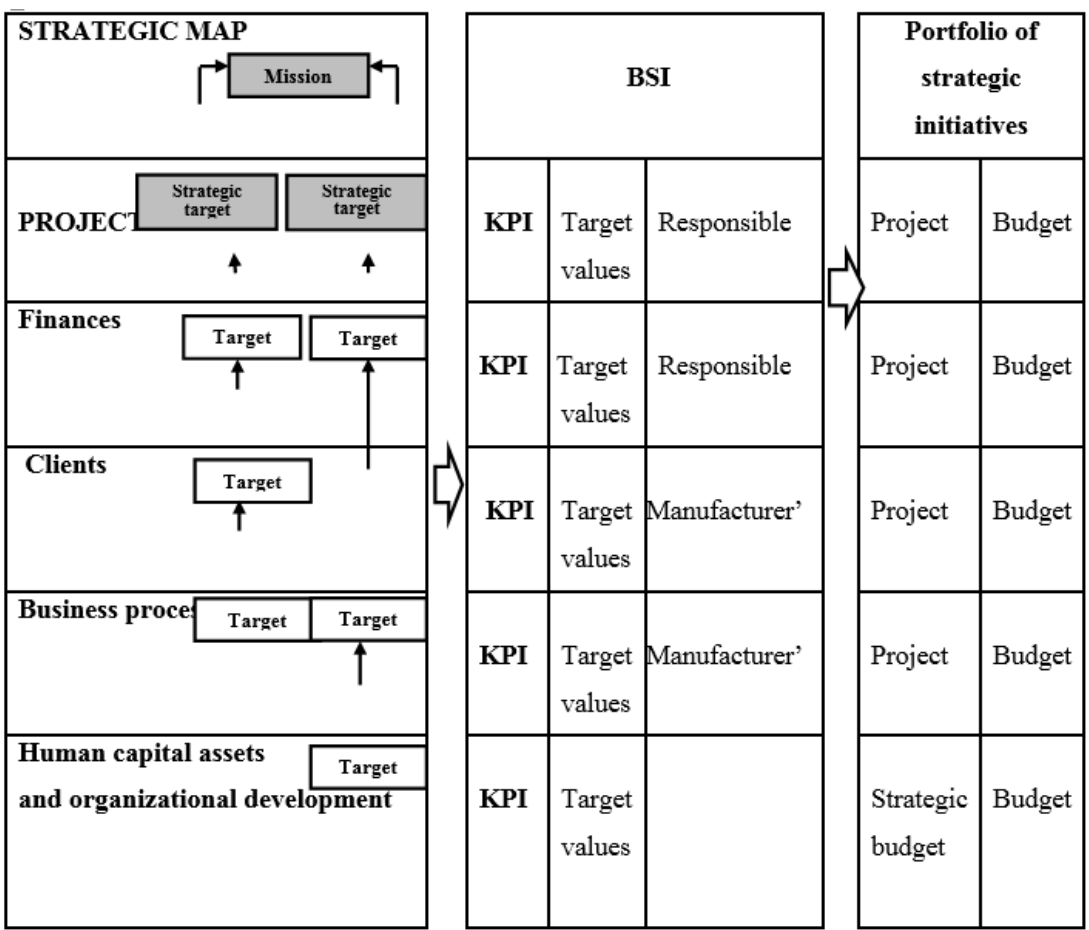

Fig.2. Structure of the harmonized system of indicators.

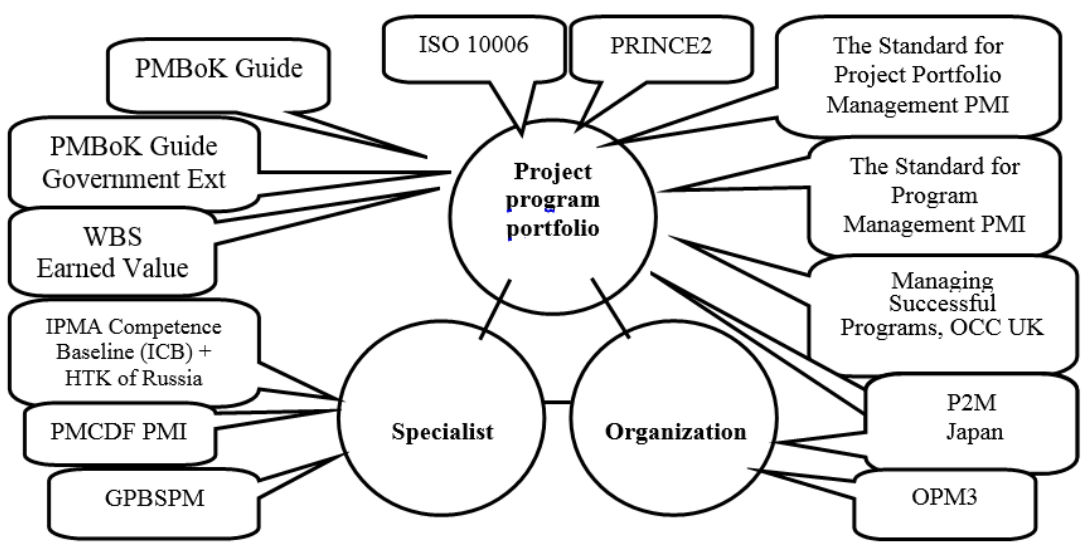

Fig.3. Standards in the field of project management.

S. A. Mishin has marked out in the project business the classical form of the triple limitation, which reflects the ratio between cost, time and quality of the project $[11,17]$. This limitation forms the project management triangle wherein each side represents a limitation, since it is impossible to implement the project with minimal terms, minimal resources and maximum quality (improvement of one parameter degrades the other two). Hence the triangle rule states that for each project at a given technical assignment there is a limiting triangle.

Actual triangle will never be placed within the limiting triangle because one vertex of the triangle will always be beyond the limiting triangle. This means that the actual triangle cannot be compressed to zero, one vertex in any case will "go out" the boundaries of a limiting triangle (Figure 5).The triangle action extends not only to the project technologies; 
so, at step-by-step product creation method the actual triangle will be far behind the limiting one by quality, terms and budget (Figure 5). The advantage of project management technology lies in the possibility to approach the boundaries of a limiting triangle [11]. Therefore, the project business needs general theoretical researches and conclusions.

In changing conditions in key points (strategic management, system designing, crises) general theoretical conclusions could become the basis of management. Fundamental science allows application of theoretical conclusions in various areas. Therefore, just this allows us to analyze particular cases and make general conclusions applicable to other cases; generating boundary cases where the applicability falls down and new conclusions come. In designing S. A. Mishin formulated the following management principles:

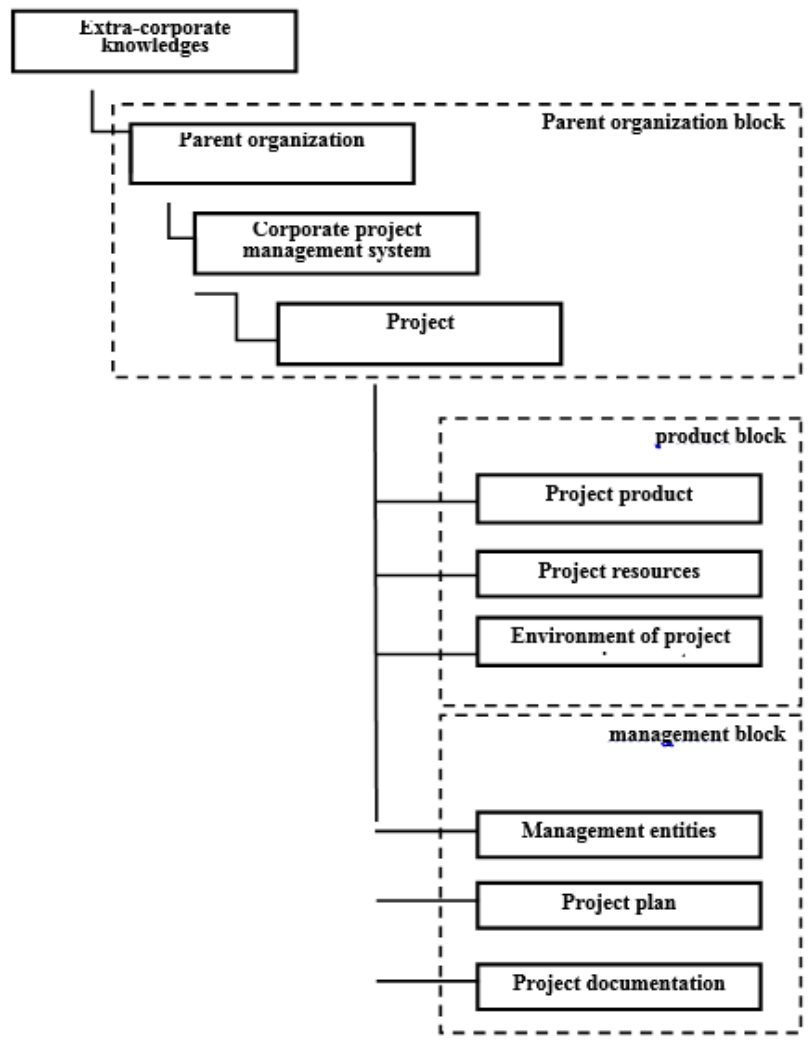

Fig.4. Structure of the project business algorithm.

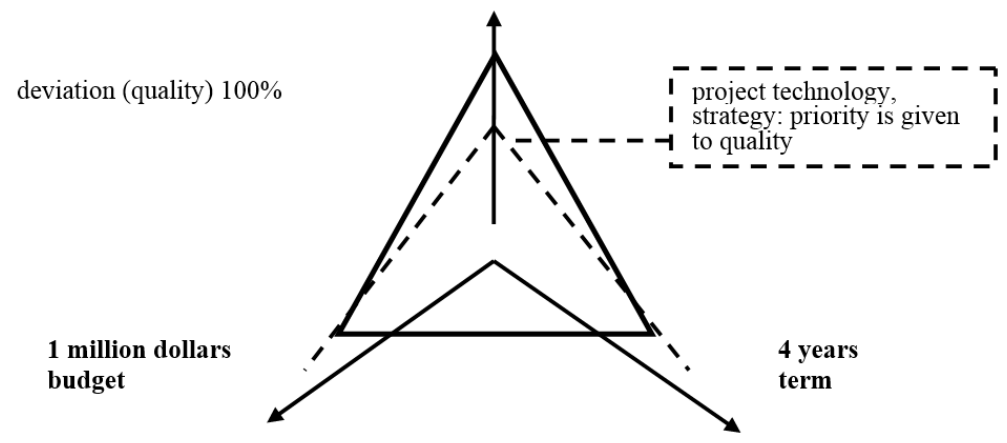

Fig. 5. Triangle of project management. Project strategies. 
Cyclicality. For the first time it was proposed by U. Schuhart who connected the production chains in a circle (specifics, production, control) (Figure6) to demonstrate the impact on the subsequent adjustment of the specification. E. Deming used the production circle of U. Schuhart in creating the cycle of management activity (Figure 7).

Sometimes Deming cycle is referred to as PDSA-cycle (Plan; Do; Study; Act), which may be used in various situations: control processes analysis, marketing cycles, etc.

The next principle is measurability, which is based on a simple assumption: manageable is what is measurable. The basic concept becomes the term "tolerable deviations", determined with the help of statistical measurements and probability theory.

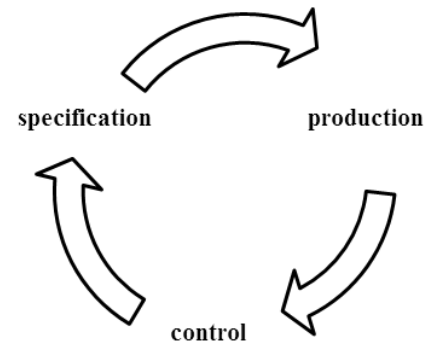

Fig.6. Linear and circular scheme of U. Schuhart.

The so-called Gauss probability distribution is often used in statistics, for which the mean square deviation (which characterizes the risk magnitude) is designated by the Greek letter sigma $-\sigma$, accordingly, business models based on the control are referred to as $3 \sigma$, $6 \sigma$. The measurability principle means measurement of management parameter son the basis of key performance indicators in comparison with the reference. Table 1 shows an example of the measurement of project plan effectiveness (in accordance with PMI standard) [11,19].

The traceability principle means that documents kept in the organization shall contain information about all history of managerial activities. Traceability completes the link: measurement - documentation - tracing.

Principle - quality as a universal category is based on the rule: prevention is better than response, and costs for deviation prevention are less than response costs after coming of deviations.

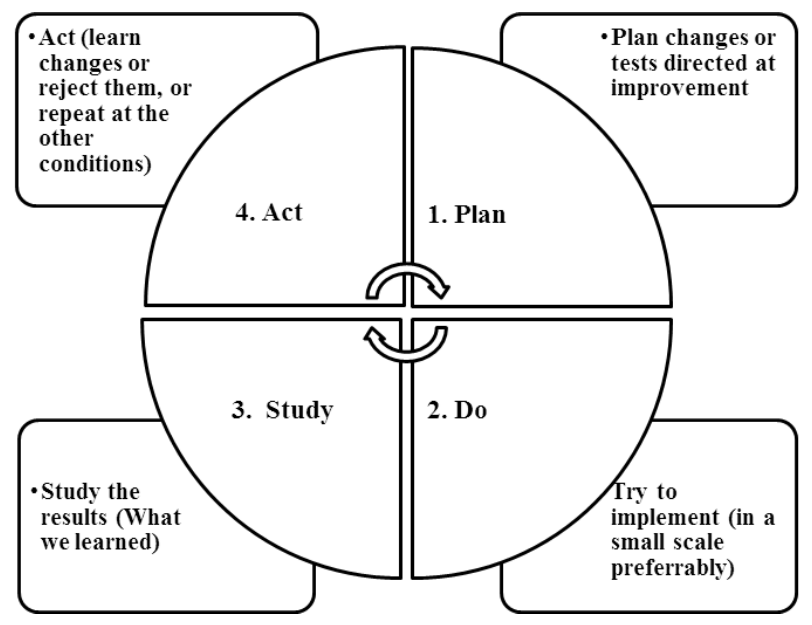

Fig.7. Deming cycle. 
Table 1. Evaluation of the project plan quality.

\begin{tabular}{|c|c|c|c|}
\hline Plan section & $\begin{array}{c}\text { Section } \\
\text { weight }\end{array}$ & $\begin{array}{c}\text { Expert evaluation of section } \\
\text { in comparison with the } \\
\text { reference }\end{array}$ & $\begin{array}{c}\text { Product of pricing by } \\
\text { weight }\end{array}$ \\
\hline Management plan & 0.06 & 6 & 0.36 \\
\hline Content management & 0.13 & 5 & 0.65 \\
\hline Project life management & 0.16 & 4 & 0.64 \\
\hline Cost management & 0.14 & 6 & 0.84 \\
\hline Quality management & 0.07 & 8 & 0.56 \\
\hline Human capital management & 0.10 & 3 & 0.30 \\
\hline Project management & 0.05 & 6 & 0.84 \\
\hline Risk management & 0.14 & 6 & 0.30 \\
\hline Contract management & 0.15 & 2 & 4.79 \\
\hline TOTAL: & 1 & & $47.9 \%$ \\
\hline
\end{tabular}

Principle of the continual improvement is a base of cyclicity, the main tool for continual improvement, since the analysis shall be carried out at each stage: what and how it is possible to improve.

During formalization of the improvement processes it is necessary to find the optimal relationship between the following two factors: 1) reduction of creative potential required for the improvement; 2) elaboration, of formalization which will make the improvement process unmanageable.

In the project business it is possible to use for the project portfolio selection the fractal analysis in optimization of the mean - variance, where the expected return for the portfolio is the mean of the expected returns by the projects. Project risk is a standard deviation of return, or $\sigma$; meanwhile it is necessary to take into account the covariance of portfolio: $\sigma_{a . b}^{2}=\sigma_{a}^{2}+\sigma_{b}^{2}+2 \times p_{a . b} \times \sigma_{a} \times \sigma_{b}$, where $p_{a . b}$ - correlation between "a" and " $b$ " projects. Optimization of the average return against variance led to appearance of the term effectiveness of mean/variance. The project business algorithm is shown in Figure 8.

Low correlation between projects, according to the fractal hypothesis, reduces the feasibility of the traditional optimization of the mean/variance. There is a possibility to use the adapted single-index Sharpe model, where the relative risk measure, beta - $b$, which is a measure of the project profitability sensitivity to the index return and is calculated: $R_{i}=a_{i}+$ $b_{i} \times I+A_{i}: b_{i}$ - sensitivity of the project $i$ to index I, $a_{i}$ - non-index project profitability, $\operatorname{Ad}_{i}$ - error parameter, with an average 0 .

Portfolio risk $c_{f} c_{p}$ is calculated as follows: $c_{f} c_{p}=\sum_{i=1}^{N} X_{i}^{a} \times c_{d i}+b_{p}^{a} \times c_{i}$, where $X_{i}-$ action $i$ weight, $c_{p}$ - portfolio variance parameter, $c_{d i}$ - variance $d_{i}$ parameter; $c_{i}$ - index variance parameter $b_{p}=\sum_{i=1}^{N} X_{i} \times b_{i}$ - portfolio profit sensitivity to I.

For normal distribution $a=2.0, c_{j}=\sigma_{j}^{2} / 2$ for $j=p, d_{i}$ and I. [13].

It is necessary to anticipate correctly the future and perform calculations, confirming the prediction in the project business. Analysis of the existing practice of project business 
allows formulation of its main characteristics: renewability allowing organization to be responsive to innovations; document insuring the expected business success. Therefore, it is possible to use methods proposed by G. Zemitan in the project forecasting [6]:

The dynamic analysis assumes that the predicted indicator $(\mathrm{Y})$ changes proportionally in the course of a certain period, therefore, the following formula is used to predict $Y$ factor: $\mathrm{Y}_{\mathrm{t}}=\mathrm{a}+\mathrm{b} \times \mathrm{t}$, where $\mathrm{t}$ - ordinal number of the period. Parameters of the regression equation $(a, b)$ are calculated by the least square method. Using the required value $t$ in the formula, the required forecast can be calculated.
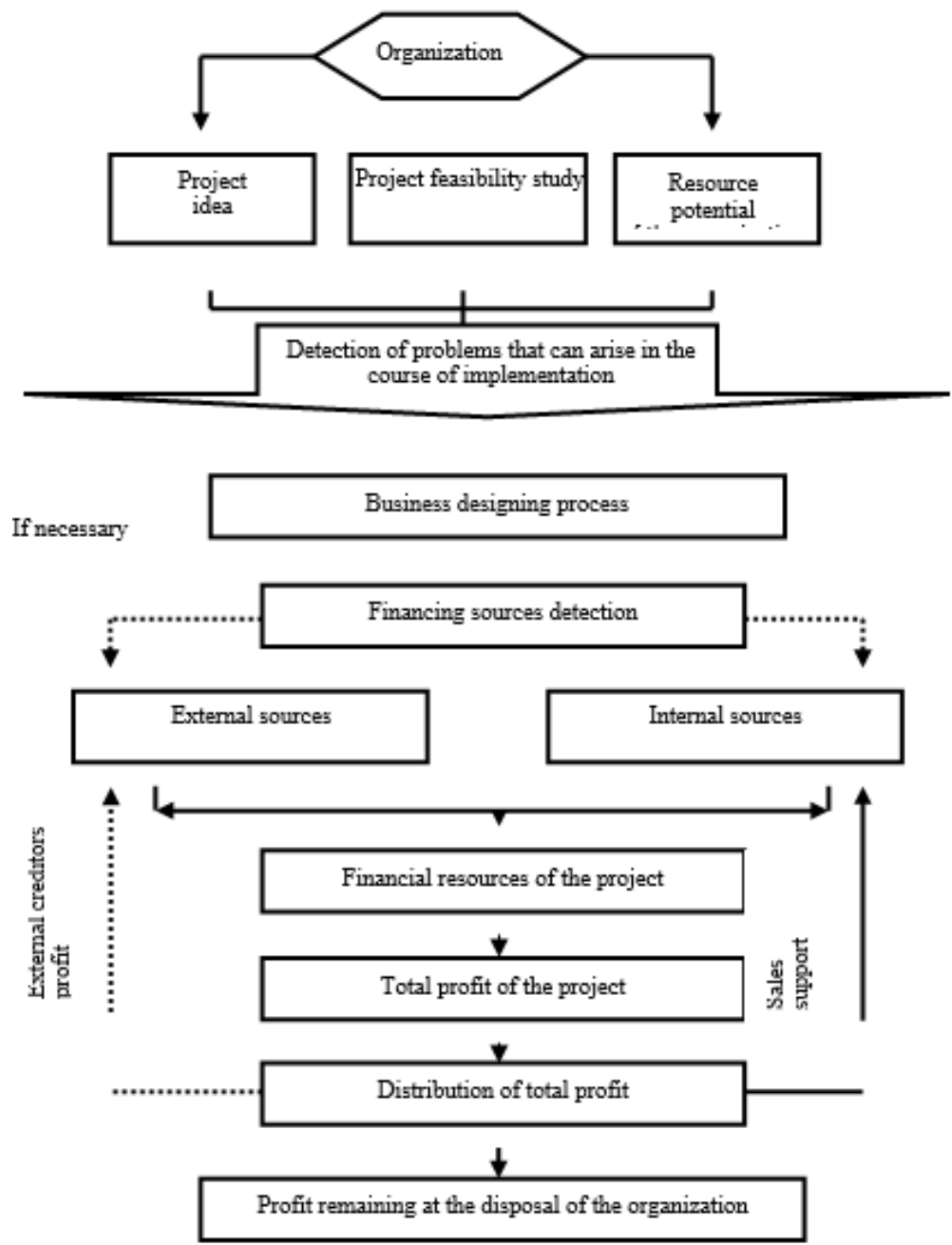

Fig. 8. Project business algorithm.

Autoregressive dependences based on the fact that all processes in the economy have interdependency and inertia. Then the autoregressive dependence equation is calculated as follows: $Y_{t}=A_{0}+A_{1} \times Y_{t-1}+\ldots+A_{i} \times Y_{t-k}$, where $Y_{t}$ - predicted value of $Y$ factor within the time interval $t ; Y_{t-i}-Y$ factor value within the time period $(t-i) ; A_{i}$ - regression coefficient of $\mathrm{i}$-th order. The accurate forecast indicators in these calculations can be obtained already at $\mathrm{k}$ $=1$. It is often used to improve the forecast accuracy, modification of this equation by introducing the time interval $t$ as a factor, thus joining the autoregressive and dynamic analysis models. Then the regression equation will be as follows: $Y_{t}=A_{0}+A_{1} \times Y_{t-1}+A_{2} \times$ 
t. Regression coefficients in this equation are calculated by the least squares method and system of equations in this case will be as follows:

$$
\begin{gathered}
\mathrm{j} \times \mathrm{A}_{0}+\mathrm{A}_{1} \times \Sigma \mathrm{Y}_{\mathrm{t}-1}+\mathrm{A}_{2} \times \Sigma \mathrm{t}=\Sigma \mathrm{Y}_{\mathrm{t}} \\
\Phi_{0} \times \Sigma \mathrm{H}_{\mathrm{e}-2}+\Phi_{1} \times \Sigma\left(\mathrm{H}_{\mathrm{e}-1}\right)^{2}+\Phi_{2} \times \Sigma\left(\mathrm{e} \times \mathrm{H}_{\mathrm{e}-1}\right)=\Sigma \mathrm{H}_{\mathrm{e}} \times \mathrm{H}_{\mathrm{e}-1} \\
\mathrm{~A}_{0} \times \Sigma \mathrm{Y}_{\mathrm{t}}+\mathrm{A}_{1} \times \Sigma\left(\mathrm{t} \times \mathrm{Y}_{\mathrm{t}-1}\right)+\mathrm{A}_{2} \times \Sigma \mathrm{t}^{2}=\Sigma\left(\mathrm{t} \times \mathrm{Y}_{\mathrm{t}-1}\right)
\end{gathered}
$$

Where $\mathrm{j}$ - series length of $\mathrm{Y}$ factor dynamics, reduced by unity. To check the correspondence of autoregressive dependence equation, the mean linear deviation value can be used: $\varepsilon=(1 / j) \Sigma\left|Y_{i}-Y_{i}{ }^{*}\right| / Y_{i}$ where $\mathrm{Y}^{*}{ }_{i}$ - calculation value of $\mathrm{Y}$ factor in $\mathrm{i}$-th time interval; $Y_{i}-$ actual value of $Y$ factor in i-th time interval. If $\varepsilon<0.15$, then auto-regression equation can be used to determine the trend of factor's dynamic series. Due to the fact that $\varepsilon$ criterion is easily calculated it is used in the regression models construction.

Multifactorial regression analysis is used in the designing due to the fact that the project forecast is built up taking into account the regression interconnection between factors. Due to the qualitative analysis $\mathrm{k}$ factors $(\mathrm{X} 1, \mathrm{X} 2, \ldots, \mathrm{Xk})$ are marked out in the predictive algorithm. These factors affect $Y$ factor and linear regression dependence is built: $Y=A_{0}+$ $A_{1} \times X_{1}+A_{2} \times X_{2}+\ldots+A_{k} \times X_{k}$, where $A_{i}$ - regression coefficients of $i$-th order $i=1,2, \ldots$, $\mathrm{k}$. Then the regression coefficients $\left(\mathrm{A}_{0}, \mathrm{~A}_{1}, \mathrm{~A}_{2}, \ldots, \mathrm{A}_{\mathrm{k}}\right)$ are determined as a result of complex mathematical calculations .

The limitation in this method is the right selection of interrelated characteristics, detection of the type of cause-and- effect link. Despite the complexity of these methods, they are effective in forecasting of systems [6].

To estimate the absolute value of the project in line with the adopted effectiveness criterion, the net current value of the project NPSV can be determined: NPSV = $\sum \frac{\mathrm{NCF}_{n} /(1+\mathrm{WACC})^{\mathrm{n}}}{(1+\mathrm{CP})^{\mathrm{n}}}=\sum \frac{\mathrm{NCF}_{\mathrm{n}}}{(1+\mathrm{CP})^{\mathrm{n}}}$, where $\mathrm{NCF}_{\mathrm{n}}$ - cash flow in the $\mathrm{n}$ period; $\mathrm{WACCN}_{\mathrm{n}}$ - average cost of capital in year $n$ (accepted not below the comparison rate). NPSV value shows the net current value of the anticipating capital growth (directed to the expanded reproduction of the project), as compared with alternative variants of investments. A positive NPSV value indicates the project effectiveness [10].

In the case when the business project cost is fulfilled on the basis of the assumption that it will last long enough, the Gordon model, that will allow rough estimation of the business project cost at each stage of its life cycle, can be used [14]. If the expected income from long-term business (useful business life $\Pi$ tends as if to infinity) is variable, but their planned dynamics assumes the continuous rate of growth $\mathrm{a}=$ const., then the formula for determination of the systematic assessment of business project PVost through capitalization of fixed income will be as follows: PVost $=C=A_{\text {nach }} / \mathrm{i}$-a, where $A_{\text {nach }}$ - operating income, expected at the initial unit period of the remaining period of business project useful life; a conditional-constant (average) income growth rate $A_{t}$ in the specified remaining period: $a=$ $\left(A_{t}-A_{t-1}\right) / A_{t-1} \frac{A_{t}-A_{t-1}}{A_{t-1}}=$ const. Life of the business project assumes that it will end even after the insignificant stable reduction in sales and profits. The above application of the Gordon model is valuable by the fact that it clearly distinguishes two control parameters in order to trust the predictive system assessment of the business project: achievement of the income level from the business after $t$ years; ensuring that for the time prior to the expiry of this period the business would provide revenues that grow with the growth rate.

Application restriction of the Gordon model for business project assessment is that the long-term growth rate a of incomes assumed as constant should be moderate: less than the discount rate $\mathrm{i}$, otherwise the business project cost as per Gordon model will give irrational results - in particular, at the rate a more than $\mathrm{i}$ (what indicates that the estimated business 
project is super lucrative), the cost will be negative; the assumption on too much large longterm growth rate of incomes is simply unrealistic [14].

If the forecasted market value of the business project or probable price of its resale is determined according to the Gordon model, it is possible to estimate its current (as of the time of assessment) equivalent $\mathrm{PV}\left(\mathrm{JX}_{\mathrm{t}}\right)$ - that is, the "maximum" price one can afford to pay for the right of resell of this business project $t_{\mathrm{Kxm}}$ years later. This is done through discounting - calculation of the current value of the possible future income from resale of the considered business project at the cost of $C_{t k n n}$ : $P V\left(C_{t k n n}\right)=C_{t k n n} /(1+i)^{t k n n} \frac{C t k n n}{(1+i)^{t} k n n}$. Evaluation concept of the business project makes it possible to assess the additional sustainability factors in the project forecasting. [14,18].

In a world of uncertainty, where once made investments are irreversible, flexibility is appreciated, idea about the possibility of choice already represents the value. Use of the real options method, proposed by R. M. Grant, provides this opportunity in the project management, valuation methodology. The project can be divided into multiple phases, allowing at each stage of the project to determine the beginning of the next phase, based on the prevailing circumstances and after studying the previous phase. Upon completion of each stage the project is evaluated again, before it "will pass through the gate" - this is an approach when developing the project. This approach produces the option value which appears due to the possibility to amend the project in the course of its implementation or suspend it, since options give the right to perform a certain action in the future. Financial options give the right to buy (sell) a certain underlying asset and insure the financial risks. Real options give the right to change project implementation progress, insure the strategic risks and are identified with certain assets of the organization, for example, patent or license, which ensure the right for product development.

The project assessment under conditions of uncertainty can be carried out with the real options method, which allows suggestion that any investment opportunity can be considered as a financial option which gives the right to create or acquire assets in the course of some time. Real options allow making optimal decisions in the future in accordance with changes. Options value depends on the collateral price, uncertainty, option validity, dividend payments and interest rate. Studies have shown that this formula makes it possible to evaluate the real options - investments, resulting from a series of choices. Table 2 shows the factors which determine the financial and real options value [4].

It is difficult to calculate the value of real options, since this is a modelling of uncertainty considering managerial decisions taken at different stages of the project. However, the basic process distinguishes by logic and consistency, therefore K. Leslie, M. P. Michaels mark out the following stages [9]:

1. Application of the discounted cash flow (DCF) analysis, not taking into account flexible options.

2. Modelling of the project uncertainty using the event tree and calculation of the discounted cash flow for various variants of uncertain factors.

3. Identification of key solutions at different points of the project execution to implement the decision tree. The feature of managerial flexibility in this case is the possibility to postpone investments in the next stage of the project, increase or decrease the project scale or refuse from its execution.

4. The total project can be estimated using the "portfolio method" which allows reproduction of the cash flows in the project with the help of the portfolio of securities and equate the project value with the "portfolio" value. 
Table 2. Six levels of financial and real options.

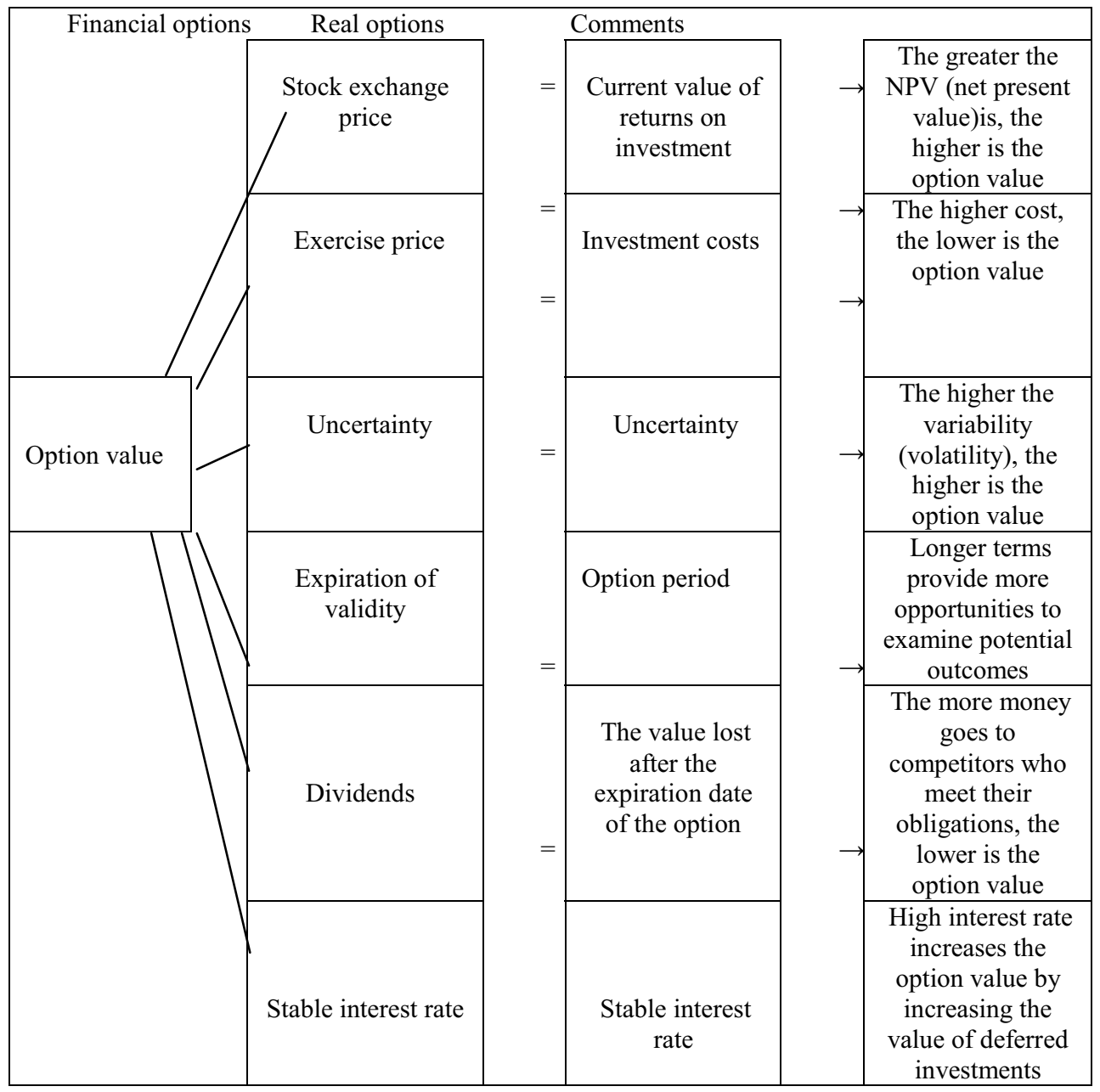

\section{Conclusion}

The project evaluation under conditions of uncertainty by option method allows increase of the enterprise flexibility and its value, reduce costs, since in this case, there is no need to carry out the whole project, but it is needed to detect just critical moments at all stages of the project. The vision with the help of option categories makes it possible to compare the flexibility value and the value of options, which creates this flexibility.

Application of monetary evaluation methodology in project management allows system analysis of the project execution at all stages, what is especially important in the strategic management, since manufacturing activity is a set of large and small projects at various life cycle stages.

\section{References}

1. V.Berezin, O.Andriyenko, Reference book of the economist, 7 (2008)

2. URL: http://kirsoft.com.ru/freedom/KSNews 227.htm/ 
3. R.M.Grant,Modern strategic analysis (SPb, St. Petersburg, 2008)

4. Knyazev D. V. Concept of forecasting and assessment of social and economic effectiveness of the investment and construction project//Economy and entrepreneurship. 8 (49), 889-893 (2014)

5. B.L.Kuznetsov, I.L. Zagitov, Economic strategies 7, 8 (2008)

6. K.Leslie, M.P. Michaels, The Real Power Options (McKinsey \& Company, 2000)

7. I.V.Matyash, Audit and financial analiz, 2 (2006)

8. S.A.Mishin, Project business: adapted model for Russia (Nuclear heating plant, Moscow, 2006)

9. V.S.Morozov, G.G. Bakulin, The Bulletin of University 9, 134-137(2014)

10. E.Peters Edgar,Fractal analysis of the financial markets. Application of the theory of Chaos in investments and economy (The Internet - trading, 2004)

11. URL: http://www.cfin.ru/finanalysis/invest/investment_efficiency.shtml

12. R.N. Shamgunov, Reference book of the economist, 4 (2010)

13. N.G.Verstina, E.M.Akimov, N.N.Taskayev,T.N.Silantyeva, Y.N. Kulakov, Innovative approach to the organization and management of a construction industry of the megalopolis 1, 1(2014)

14. N.G.Verstina, D.A.Semernin, MGSU Bulletin 5, 290(2011)

15. URL: www.iteam.ru

16. A.Mottaeva, MATEC 73, 11 (2016)

17. A.Mottaeva, A.Zheltenkov,I.Stukanova,S.Ryabichenko, S.Zhuk, MATEC, 73, 13(2016)

18. E.Stein, N.Taskaeva, E. Chibisova, Procedia Engineering165, 1410-1416, 2016

19. T.Miroshnikova, N.Taskaeva, MATEC 73, 07006(2016) 